\title{
PSYCHOMETRIC TESTING AND HUMAN RESOURCE MANAGEMENT
}

\author{
R P VAN DER MERWE \\ Department of Industrial and Organisational Psychology \\ University of Port Elizabeth
}

\begin{abstract}
This is a cumulative report on the findings of various exploratory research that were done with regard to the practice of psychometric testing in the Eastern Cape. Recent and ongoing developments in the South African labour legislation, and especially the implications of the Employment Equity Act, highlight once again the importance of the validation of all instruments to be used for human assessment and selection purposes.

Information was gathered to establish which psychometric tests are used, and for what purposes, in industry today. Biographical information on each organisation is supplied, including the number of employees. The role of psychometric testing in the selection procedure is discussed. The different tests used, as well as the test users, are also indicated. The findings of other, related research, as well as comments, recommendations and shortcomings, are discussed.
\end{abstract}

\section{OPSOMMING}

Hierdie is ' $n$ kumulatiewe verslag wat die resultate verstrek van verskeie verkennende ondersoeke wat gedoen is na die aanwending van psigometriese toetsing in die Oos-Kaap. Onlangse en voortdurende ontwikkelinge in die SuidAfrikaanse arbeidswetgewing, en veral die implikasies van die Wet op Gelyke Indiensneming, beklemtoon weer eens die belangrikheid van die validering van enige instrumente wat gebruik word vir evaluerings- en keuringsdoeleindes van individue.

Inligting is ingewin om te bepaal watter psigometriese toetse, sowel as vir watter doel, vandag in die bedryf gebruik word. Biografiese inligting oor die onderskeie organisasies, insluitende hul aantal werknemers, word verstrek. Die rol van psigometriese toetsing in die keuringsproses word bespreek. Die verskillende toetse wat deur die organisasies gebruik word, sowel as die toetsgebruikers, word ook aangedui. Die bevindinge van ander, relevante navorsing, sowel as opmerkings, aanbevelings en tekortkominge word bespreek.

One of the critical elements in ensuring outstanding organisational performance, is the selection and development of excellent staff. International as well as local research has demonstrated the role that psychometric assessment can play in significantly improving the selection process for both new entrants and internal promotions. Effective psychometric assessment can also play a key role in staff development processes - an important challenge presently facing South Africa.

Psychometric tests are commonly employed as aids in occupational decisions, including the selection and classification of human resources. From the assemblyline operator or filing clerk, to top management, there is scarcely a type of job for which some kind of psychometric test has not proved helpful in such matters as hiring, job assignment, transfer, promotion, or termination (Anastasi \& Urbina, 1997).

According to Owen and Taljaard (1996), it appears that psychometric tests can contribute to the efficiency of selection and placement in industry, if used carefully and responsibly. Friedenberg (1995) referred to research which compared different selection procedures (application forms, letters of reference, interviews, testing) and confirmed that although each technique has its own merits, standardised tests are the most psychometrically sound.

Moerdyk, in an article by Mittner (1998), also mentioned that if psychometric tests are handled with insight and sensitivity, they remain the most effective way of predicting behaviour. Kemp (1999) said that tests are an aid in the selection process and if used properly, supply invaluable information which is not easily gleaned in interviews. According to Van der Walt (1998), experience has proved that tests are generally much more reliable and more valid than other techniques. Van der Walt (1998) also mentioned that studies in trade and industry have

Requests for copies should be addressed to: RP van der Merwe, Department of Industrial and Organisational Psychology, University of Port Elizabeth, PO Box 1600 , Port Elizabeth, 6000 indicated that psychometric tests are about four times more effective than screening interviews.

Given the high costs of staff turnover and the heightened importance of identifying key staff from previously disadvantaged groups, psychometric assessment can make a major contribution to human resource management in South Africa. In the light of the abovementioned information, it was decided to investigate the use of psychometric tests in human resource management. This study is the final, cumulative report on the findings of various such exploratory research (Van der Merwe, 1999, 2000) that was undertaken to establish which psychometric tests are used, and for what purposes, in industry today.

Latest legislation

To protect the public against abuses, the use of psychometric tests is legally specified (Medical, Dental and Supplementary Health Service Professions Act, 1974). Specialised training is required to determine which tests will give the best results in the particular circumstances and to interpret the results responsibly. Tests may only be used by registered psychologists or other suitably qualified and registered persons under the supervision of psychologists.

Recent and ongoing developments in the South African labour legislation, emphasise once again the need for the responsible use of psychometric tests and other psychological assessment procedures. According to Eckstein (1998), the Employment Equity Act highlights the importance of the validation of any instruments to be used for assessment and selection purposes. This is a definite move towards making selection decisions more scientific. Kriek (1998) also welcomes this legislation which, according to him, can only help to improve current assessment practices in South Africa. According to Roodt (1998), one of the purposes of the Act is to ensure that psychometric tests are used in an unbaised manner, resulting in fairness.

The Employment Equity Act (1998, p.8) inter alia determines the following: 
"Psychological testing and other similar assessments of an employee are prohibited unless the test or assessment being used -

a) has been scientifically shown to be valid and reliable;

b) can be applied fairly to all employees; and

c) is not biased against any employee or group"

To deal with this in practice, one will first of all need a good and accurate method of job analysis - breaking down the job into dimensions or competencies. Next one would need simple and verifiable tests for these job related competencies - such as work sample tests or assessment centres. One would of course also have to keep statistics of applicants at all stages of the selection process, so as to defend oneself against any allegations of differential impact.

\section{The selection process}

There is no fixed, generally accepted, standard selection procedure that is at present used by everybody. A selection procedure may be fairly simple or very complex, depending on the nature of the organisation, the task for which individuals are being selected, and the philosophy of human resource management (Aiken, 1994).

The vast majority of employee selection programs are based upon the successive-hurdle technique. This means that to be hired, applicants must successfully pass various screening steps. At each step or hurdle some candidates get rejected. Psychometric tests can be of great value in employee selection because of their objectivity and validity (Schultz \& Schultz, 1998). It must however be regarded as only one possible step in the selection process - merely an aid, never to be used on its own, or to replace the whole selection procedure. The general nature of the selection process is set out in Figure 1.

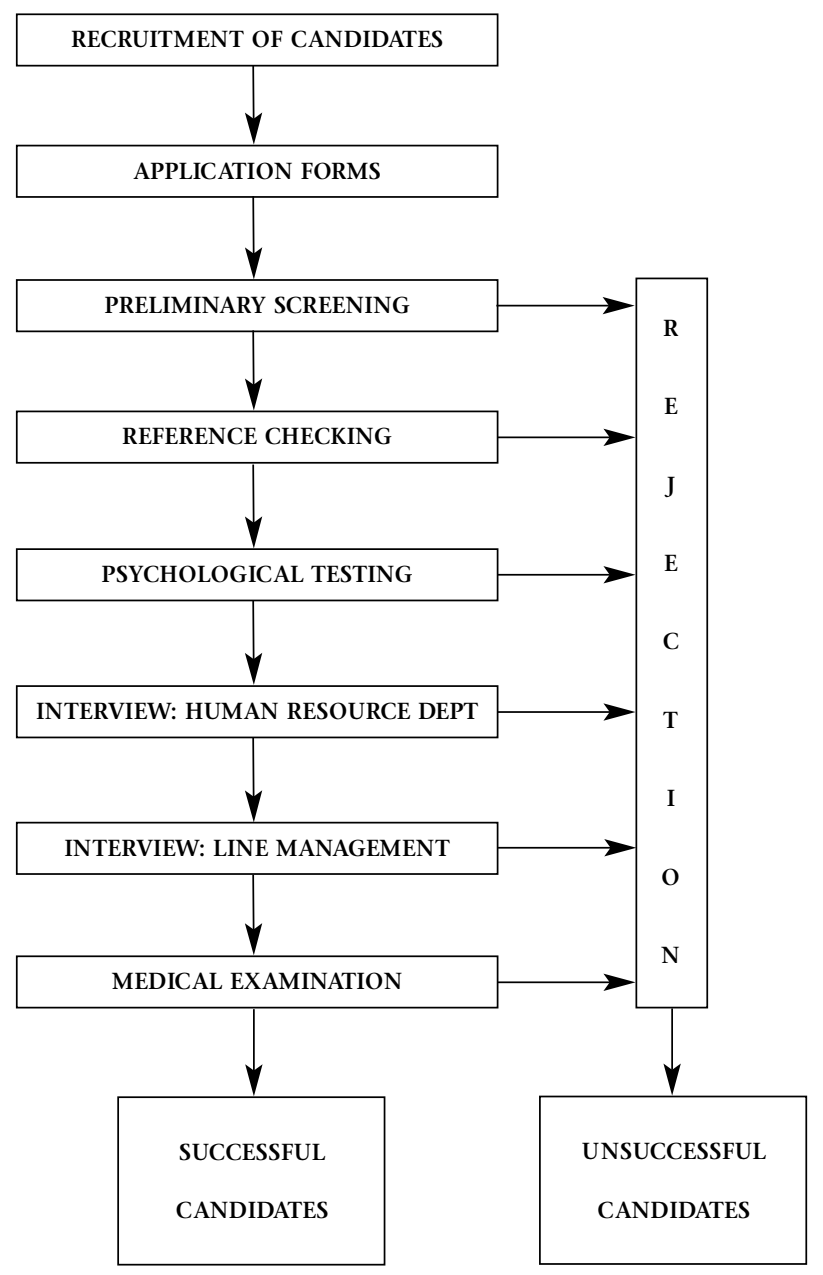

Figure 1: THE SELECTION PROCESS

\section{METHOD}

Sample

A non-probability convenience sample of organisations was drawn from the Port Elizabeth and Uitenhage areas of the Eastern Cape Province. This was initial, exploratory research that should be regarded as a qualitative investigation. Background information on the various organisations that were selected, are supplied in Table 1.

\section{TABLE 1}

Participating Organisations

\begin{tabular}{|c|c|c|}
\hline $\begin{array}{l}\text { Organi- } \\
\text { sation }\end{array}$ & Type of business & Employees \\
\hline A & $\begin{array}{l}\text { Branch of large insurance company (nation wide } \pm \\
13000 \text { employees) }\end{array}$ & 600 \\
\hline B & $\begin{array}{l}\text { Branch of large banking group (nation wide } \pm \\
37000 \text { employees) }\end{array}$ & 1300 \\
\hline $\mathrm{C}$ & $\begin{array}{l}\text { Government department responsible for security, } \\
\text { law and order }\end{array}$ & 19000 \\
\hline $\mathrm{D}$ & $\begin{array}{l}\text { Branch of large beverage company (nation wide } \pm \\
8000 \text { employees) }\end{array}$ & 1000 \\
\hline $\mathrm{E}$ & Motor manufacturing company & 6500 \\
\hline $\mathrm{F}$ & $\begin{array}{l}\text { Regional office of telecommunications company } \\
\text { (nation wide } \pm 57000 \text { employees) }\end{array}$ & 4500 \\
\hline G & Motor manufacturing company & 4000 \\
\hline $\mathrm{H}$ & $\begin{array}{l}\text { Technical and network services business unit of } \\
\text { telecommunications company (nation wide } \pm \\
57000 \text { employees) }\end{array}$ & 2000 \\
\hline I & Tyre manufacturing company & 2000 \\
\hline $\mathrm{J}$ & Company manufacturing lights & 440 \\
\hline K & Textile company & 1595 \\
\hline $\mathrm{L}$ & Company manufacturing pharmaceuticals & 860 \\
\hline M & Provincial office of large banking group & 200 \\
\hline $\mathrm{N}$ & Company manufacturing vehicle accessories & 453 \\
\hline $\mathrm{O}$ & $\begin{array}{l}\text { Branch of large beverage company (nation } \\
\text { wide } \pm 3000 \text { employees) }\end{array}$ & 700 \\
\hline $\mathrm{P}$ & Local government department & 7000 \\
\hline Q & $\begin{array}{l}\text { Company involved in processing of wheat and } \\
\text { maize products }\end{array}$ & 600 \\
\hline $\mathrm{R}$ & Company manufacturing vehicle accessories & 200 \\
\hline$S$ & $\begin{array}{l}\text { Branch of banking group (nation wide } \pm 706 \\
\text { employees) }\end{array}$ & 70 \\
\hline $\mathrm{T}$ & Company manufacturing vehicle accessories & 500 \\
\hline
\end{tabular}

From Table 1 it appears that the participating organisations cover a wide range of different economic activities.

\section{Procedure}

Postgraduate students in Industrial and Organisational Psychology acted as field workers in this study. They were thoroughly briefed by the researcher on the interviewing procedure to be used for this research. The data was collected by means of individual interviews that these students conducted with a designated representative from the human resource department of each organisation that was involved.

Mostly these representatives were personally responsible for testing in their organisations. Where this was not the case, the 
representative was the person locally involved with the arrangements and administration regarding testing in that organisation. These people provided the information that was used in this research, by discussing the testing policy of their organisation with the interviewers.

\section{Data analysis}

All the data gathered by means of these interviews, was analysed by means of content analysis. Inferences were made on inspection of the data gathered.

\section{RESULTS}

The results of this research are presented in the following format: Brief testing policy of the organisation

Tests used in the organisation

Test users (administrators) in the organisation

Comments by organisational representatives

Based on the questions asked during the interviews, the following information on each organisation, was made available.

\section{Brief testing policy}

Whether an organisation has a clearly defined selection procedure or not, as well as which steps are included in it, are indicated in Table 2.

TABLE 2

SELECTION PROCEDURE IN ORGANISATIONS

\begin{tabular}{|c|c|c|c|c|c|}
\hline $\begin{array}{l}\text { Organi- } \\
\text { sation }\end{array}$ & $\begin{array}{c}\text { Clear } \\
\text { procedure }\end{array}$ & $\begin{array}{c}\text { Application } \\
\text { blank/CV }\end{array}$ & Interviews & $\begin{array}{l}\text { Psychometric } \\
\text { testing }\end{array}$ & $\begin{array}{l}\text { Referemce } \\
\text { checking }\end{array}$ \\
\hline $\mathrm{A}$ & $\mathrm{X}$ & $\mathrm{X}$ & $\mathrm{X}$ & $\mathrm{X}$ & $\mathrm{X}$ \\
\hline B & $X$ & $X$ & $\mathrm{X}$ & $\mathrm{X}$ & \\
\hline $\mathrm{C}$ & $\mathrm{X}$ & $\mathrm{X}$ & $X$ & $\mathrm{X}$ & $X$ \\
\hline $\mathrm{D}$ & $\mathrm{X}$ & $\mathrm{X}$ & $\mathrm{X}$ & $\mathrm{X}$ & $X$ \\
\hline E & $X$ & & $\mathrm{X}$ & $X$ & \\
\hline $\mathrm{F}$ & $\mathrm{X}$ & $\mathrm{X}$ & $X$ & $\mathrm{X}$ & $X$ \\
\hline G & $\mathrm{X}$ & $\mathrm{X}$ & $\mathrm{X}$ & $X$ & $\mathrm{X}$ \\
\hline $\mathrm{H}$ & $\mathrm{X}$ & $\mathrm{X}$ & $\mathrm{X}$ & $X$ & \\
\hline I & $\mathrm{X}$ & $\mathrm{X}$ & $\mathrm{X}$ & $\mathrm{X}$ & $X$ \\
\hline $\mathrm{J}$ & & & $\mathrm{X}$ & $\mathrm{X}$ & $X$ \\
\hline K & $\mathrm{X}$ & $X$ & $\mathrm{X}$ & $X$ & $\mathrm{X}$ \\
\hline $\mathrm{L}$ & $\mathrm{X}$ & $\mathrm{X}$ & $X$ & $\mathrm{X}$ & \\
\hline M & & $\mathrm{X}$ & $X$ & $\mathrm{X}$ & \\
\hline $\mathrm{N}$ & & $\mathrm{X}$ & $\mathrm{X}$ & $\mathrm{X}$ & \\
\hline $\mathrm{O}$ & & $\mathrm{X}$ & $\mathrm{X}$ & $\mathrm{X}$ & \\
\hline $\mathrm{P}$ & $\mathrm{X}$ & $\mathrm{X}$ & $\mathrm{X}$ & $\mathrm{X}$ & $X$ \\
\hline Q & $\mathrm{X}$ & $\mathrm{X}$ & $X$ & $\mathrm{X}$ & $\mathrm{X}$ \\
\hline $\mathrm{R}$ & & $\mathrm{X}$ & $X$ & $X$ & $\mathrm{X}$ \\
\hline S & & $\mathrm{X}$ & $\mathrm{X}$ & & $X$ \\
\hline $\mathrm{T}$ & $\mathrm{X}$ & & & $X$ & \\
\hline
\end{tabular}

With reference to Table 2, the role of psychometric testing in the selection procedure, as well as the levels at which tests are applied in each of the organisations, are now discussed.
Organisation A

In the case of organisation A, psychometric tests are merely used as an additional aid in the selection process and are required to be culture-fair and non-discriminatory. Employment equity enjoys a high priority in this organisation. Tests are used for selection and management information, and are used more at the lower levels of employment. At management level assessment centres are used for selection and promotion purposes.

\section{Organisation B}

This organisation uses a clearly defined selection procedure which was recently revised to comply with the latest labour legislation. Their approach is that it is not always equally important to use psychometric tests in the selection process. The specific job one is selecting for, will indicate whether it is necessary to do testing or not. Tests are never used on their own - always together with an interview and other input. Tests are used at all levels in this organisation, for selection, placement, promotion and strategic restructuring. They do not make use of assessment centres because they regard them as too expensive and time consuming.

\section{Organisation C}

In organisation $\mathrm{C}$ tests are never chosen at random - a thorough job analysis is first conducted to determine the skills that are needed to perform the job successfully. Tests are used at all levels in this organisation: for selection, placement, training and transfers, but not for promotions. Although they previously made use of assessment centres, these are no longer in use.

\section{Organisation D}

Psychometric tests are regarded as important in this organisation's selection process. The purpose of psychometric tests is to provide specialist information in support of managerial decision-making, by increasing the accuracy of decisions regarding the selection, promotion and development of employees. The assessments are also aimed at assisting individual employees in gaining insight into themselves, for the purpose of their own self-development. Tests are used in this organisation for all positions from shopfloor level to higher positions. They are however also used for certain positions where specific psychometric and psychological make-up is deemed necessary (i.e. apprentices and bursars).

\section{Organisation E}

In this organisation all information gathered during the selection process is used to make a final appointment decision. Tests are mainly used for selection purposes - mostly at managerial level, although in some cases they are also used at a few entry grade levels.

Organisation $F$

In organisation $\mathrm{F}$ the approach is not to use tests in isolation, but rather as a means of verifying the information obtained from the other selection devices. Tests are used to facilitate selection, placement and promotion decisions. They are also used for development and training purposes. Tests are administered at all levels, from auxillary, lower-level positions to management positions.

\section{Organisation $G$}

This organisation sometimes uses assessment centers, but they are doing it less and less. The primary reasons being that it is very expensive, extremely time consuming and that there has to be fairly intensive training of the raters involved. They employ psychometric tests for selection, placement, promotions, as well as to establish training needs. Tests are used at the lower levels of the organisation, as well as when selecting candidates for supervisory positions or management level. 


\section{Organisation $H$}

In this organisation the results of the tests are evaluated along with the outcomes of the other procedures that are used. Tests are mainly used for selection purposes, although they are also considering using it for development purposes. When dealing with higher level positions, exercises including case studies and simulations, are occasionally also implemented.

\section{Organisation I}

In organisation I pychometric testing is also used for promotion purposes, to determine training needs, and for counselling. It is however regarded as an additional tool to be used, to try and inject some objectivity into what could otherwise be a very subjective process. It is used extensively at labourer entrance level, as well as for recruitment at management level.

\section{Organisation J}

In the case of organisation $\mathrm{J}$, they only started using psychometric testing recently and it will only be used on supervisory and managerial positions. Because it is a relatively small company, assessment centres are not used - it is too costly.

\section{Organisation $K$}

This organisation also uses psychometric tests for promotion purposes - especially for supervisory and managerial positions.

\section{Organisation $L$}

In this organisation psychometric testing is also used for career development, identification of training needs and counselling. It appears that tests are used at all different levels (from operational to managerial) in this company.

\section{Organisation $M$}

In organisation $\mathrm{M}$ psychometric tests are also used for performance appraisals, career guidance and in assessing managerial potential. Tests are used at all different levels in this organisation.

\section{Organisation N}

In this organisation psychometric testing does not only play an important role in their selection procedure, but is also used for the promotion of present employees. Different tests are used for the different levels of employment in the organisation.

\section{Organisation $O$}

In this organisation it is part of their policy to use psychometric tests to provide additional information about candidates when making selection or human resource development decisions. In no instances is this information to be used in isolation. Testing is conducted from supervisory level up to management level.

\section{Organisation $P$}

In this organisation psychometric testing is used only for the selection of apprentices - and nothing else, because they are concerned about the culture-fairness of the tests.

\section{Organisation Q}

In organisation $Q$ psychometric testing is only used in situations where uncertainty exists with regard to candidates. It is however also used for promotion purposes and for development of employees - at most levels in the company. They also make extensive use of an assessment centre - only for senior management level and higher positions.

\section{Organisation $R$}

This organisation extensively makes use of employment agencies to recruit people for them. Testing is mainly used with uppermanagement, for selection, promotion as well as identifying leadership potential.

\section{Organisation S}

This organisation does not regard psychometric testing as essential in the selection of employees. They do however make use of graphology for senior positions to determine leadership potential. They also make use of competencybased assessment.

\section{Organisation $T$}

In this organisation psychometric tests are used mainly for selection purposes, as well as performance counselling and identifying people with potential for development. They have decided to outsource most of their human resource functions, including the administration of psychometric tests.

Tests used

In Table 3 the various tests used by the different organisations are indicated. Note that quite a few tests are used by only one or two organisations. Some tests are used by three or more organisations, and the most widely used test is the $16 \mathrm{PF}$, which is used by fifteen of these organisations. For greater clarity, a brief description of the abbreviations used to indicate the different tests, follows.

Sixteen Personality Factor Questionnaire (16 PF): It measures 16 primary personality traits and is used inter alia in industry and business in selection, placement and promotion of employees by predicting important job related criteria such as work efficiency, tolerance of routine etc (Huysamen, 1996; Spangenberg, 1990).

South African Wechsler Adult Intelligence Scale (SAWAIS): This test is a verbally administered individual scale that was designed to evaluate the intellectual functioning of the older child and adult (Huysamen, 1996; Spangenberg, 1990).

Intermediate Battery (INT Bat): This battery was designed to measure certain mental abilities, including mental alertness, arithmetical ability, some aspects of language, and clerical skills. It can be used in vocational guidance as well as for the selection of persons who have received not more than 12 years of schooling (Huysamen, 1996; Owen \& Taljaard, 1996; Spangenberg, 1990).

Minnesota Multiphasic Personality Inventory (MMPI): It is a broad-band test designed to assess a number of the major patterns of personality and emotional disorders. To a certain extent it highlights signs of pathology in people being tested (Aiken, 1994; Anastasi \& Urbina, 1997).

Senior Aptitude Tests (SAT): This test was designed to measure a number of aptitudes and the results can be used for vocational guidance and selection purposes (Huysamen, 1996; Owen \& Taljaard, 1996).

Career Path Appreciation (CPA): This is based on a stratified systems theory and assesses a manager's ability to deal with challenges of varying complexity. Judgement in making decisions under a variety of conditions of uncertainty is assessed, along with the ability to adopt long-term and shortterm thinking. This evaluation works on a semi-structured interview system.

Dover/Vienna Test System (DOVER): This is a machine with lights of different colours and the testee is expected to coordinate the hand switches with the different lights of the machine as they come on and go off. The performance of the candidate is scored automatically. Performance under stress, orientation ability, levels of productivity, and learning ability, are some of the aspects evaluated by this system.

High Level Figure Classification Test (HL FCT): This is a nonverbal pencil and paper test which measures abstract reasoning ability. It is intended for use in selecting staff for positions which require a moderate to high level of abstract conceptual functioning - more than mere routine activities (Spangenberg, 1990). 
TABLE 3

TESTS USED BY DIFFEENT ORGANISATIONS

\begin{tabular}{|c|c|c|c|c|c|c|c|c|c|c|c|c|c|c|c|c|c|c|c|c|}
\hline ORGANISATION: & A & B & $\mathrm{C}$ & D & E & $\mathrm{F}$ & G & $\mathrm{H}$ & I & $\mathrm{J}$ & K & L & M & $\mathrm{N}$ & o & $\mathbf{P}$ & Q & $\mathbf{R}$ & $s$ & $\mathrm{~T}$ \\
\hline \multicolumn{21}{|l|}{ TESTS: } \\
\hline $16 \mathrm{PF}$ & $\mathrm{X}$ & $\mathrm{X}$ & $\mathrm{X}$ & & $\mathrm{X}$ & $\mathrm{X}$ & $\mathrm{X}$ & & $\mathrm{x}$ & $\mathrm{X}$ & $\mathrm{x}$ & $\mathrm{x}$ & $\mathrm{X}$ & $\mathrm{X}$ & & $\mathrm{X}$ & $\mathrm{X}$ & & & $\mathrm{X}$ \\
\hline SAWAIS & & $\mathrm{X}$ & $\mathrm{X}$ & & & $\mathrm{X}$ & & & & & & $\mathrm{x}$ & & $\mathrm{X}$ & & & & & & $\mathrm{X}$ \\
\hline INT Bat & $\mathrm{x}$ & $\mathrm{X}$ & $\mathrm{X}$ & & & & & & & & & $\mathrm{X}$ & & & & $\mathrm{X}$ & & & & \\
\hline MMPI & & & & $\mathrm{x}$ & & & & & & $\mathrm{X}$ & & & & $\mathrm{X}$ & & & & & & $\mathrm{X}$ \\
\hline SAT & $\mathrm{X}$ & & $\mathrm{X}$ & & & $\mathrm{X}$ & $\mathrm{X}$ & & & & & & & & & & & & & \\
\hline $\mathrm{CPA}$ & & & & $\mathrm{x}$ & & & & & & & & & $\mathrm{X}$ & & $\mathrm{X}$ & & & & $\mathrm{X}$ & \\
\hline DOVER & & & & & $\mathrm{X}$ & & & & $\mathrm{X}$ & $\mathrm{X}$ & & & & $\mathrm{X}$ & & & & & & \\
\hline HL FCT & & & & & & $\mathrm{X}$ & $\mathrm{X}$ & $\mathrm{X}$ & & & & & & & & $\mathrm{X}$ & & & & \\
\hline $\mathrm{OPQ} / \mathrm{CCSQ}$ & & & & & & $\mathrm{X}$ & & $\mathrm{X}$ & & & & & $\mathrm{X}$ & & $\mathrm{X}$ & & & & & \\
\hline PPA & & & & & & & & & $\mathrm{x}$ & & & & & & $\mathrm{X}$ & & & $\mathrm{x}$ & $\mathrm{X}$ & \\
\hline MBTI & $\mathrm{X}$ & & & & & $\mathrm{X}$ & $\mathrm{X}$ & & & & & & & & & & & & & \\
\hline GI Exerc & & & & & $\mathrm{X}$ & & & & & & & $\mathrm{x}$ & & & & & $\mathrm{X}$ & & & \\
\hline PRESENTATION & & & & & $\mathrm{X}$ & & & & & & & $\mathrm{x}$ & & & & & $\mathrm{X}$ & & & \\
\hline IN-BASKET & & & & & $\mathrm{X}$ & & & & & & & $\mathrm{x}$ & & & & & $\mathrm{X}$ & & & \\
\hline SORT & & $\mathrm{X}$ & $\mathrm{X}$ & & & & & & & & & & & & & & & & & \\
\hline $19 \mathrm{FII}$ & $\mathrm{x}$ & & & & & & & & & & & $\mathrm{x}$ & & & & & & & & \\
\hline HL Bat & $\mathrm{X}$ & $\mathrm{X}$ & & & & & & & & & & & & & & & & & & \\
\hline SDS & & & & & & $\mathrm{X}$ & & & & & & & & & & $\mathrm{X}$ & & & & \\
\hline РТВ/ТTВ & & & & & & $\mathrm{X}$ & & $\mathrm{X}$ & & & & & & & & & & & & \\
\hline TAT & & $\mathrm{X}$ & & & & & & & & & & & & & & & & & & \\
\hline NORM Bat & & $\mathrm{X}$ & & & & & & & & & & & & & & & & & & \\
\hline AAT & & & $\mathrm{X}$ & & & & & & & & & & & & & & & & & \\
\hline РАB & $\mathrm{x}$ & & & & & & & & & & & & & & & & & & & \\
\hline MGIB/CRTB/CCAS & & & & & & & & & & & & & & & $\mathrm{X}$ & & & & & \\
\hline BLOX & & & & & & & & & & & & & & & & $\mathrm{X}$ & & & & \\
\hline RAVEN'S & & & & & & & & & & & & $\mathrm{x}$ & & & & & & & & \\
\hline MECHANICAL & & & & & & & & & & & & & & & & $\mathrm{X}$ & & & & \\
\hline
\end{tabular}

SHL Occupational Personality Questionnaire (OPQ): This questionnaire is applied to assess a comprehensive range of personality characteristics, including: relationships with people; thinking and problem-solving style; emotions, motivation and drives; team working styles; leadership or subordinate styles; selling and influencing styles (SHL, 1996).

SHL Customer Contact Styles Questionnaire (CCSQ): This questionnaire has been designed to measure sixteen dimensions of personality relevant for non-supervisory staff working in sales or customer service roles (SHL, 1996).

Thomas Personal Profile Analysis (PPA): This is a questionnaire in which the person being evaluated has to select the words which most and least describe him/her. By charting these choices scientifically, insight is obtained into how this person will behave in the work situation. It can provide helpful understanding as to how this person copes with his/her environment and what his/her present attitudes are likely to be. It also provides insight into possible performance in a particular function (Thomas International, undated).

Myers-Briggs Type Indicator (MBTI): This test was designed to implement Jung's theory of type, as understood by the author (Isabel Myers). More specifically the aim is to identify the basic preferences of people with regard to perception and judgement. These preferences are: Extraversion-Introversion, SensingIntuition, Thinking-Feeling, and Judgement-Perception (Spangenberg, 1990).

Group Interaction Exercise (GI Exerc): This can be regarded as a group problem solving exercise. The group of candidates is given a problem to discuss and within fifteen minutes they must come to a solution. Afterwards, each member of the group's contribution is evaluated and considered, to determine if it contributed to the final outcome reached by the group.

Presentation: This exercise is similar to the previous (group interaction exercise) except that the candidate works as an individual. The candidate is given a problem and allowed five minutes to think about a way of solving it. Then the candidate has to make an oral presentation, debating and demonstrating how the problem can best be solved.

In-basket Exercise: This exercise consists of samples of typical items or activities found in the department in which the vacancy exists. Candidates are asked to indicate what action should be taken with regard to each item or activity. In other words, it is a type of simulation exercise in which the person must deal with a pile of paperwork - letters, reports, phone messages, and so on - typical of what might be found in a manager's in-basket.

Structured-Objective Rorschach Test (SORT): The SORT is based on the traditional Rorschach Test and its aim is to obtain psychologically meaningful data by means of which a broad overall picture of the individual can be obtained (Spangenberg, 1990). Together with data from other tests, this can then be used for counselling, selection and the prediction of job success.

Nineteen Field Interest Inventory (19 FII): This inventory measures occupational interests with respect to 19 broad fields 
of activity. It also measures the extent to which a person is actively or passively interested in the 19 fields, as well as the extent to which the interests are work- or hobby-related (Owen \& Taljaard, 1996).

High Level Battery (HL Bat): This battery provides a measurement of general intelligence, arithmetical ability and certain language abilities. It can be used for vocational guidance as well as the selection and classification of high level employees, and is suitable for testees with matric or higher qualifications (Huysamen, 1996; Owen \& Taljaard, 1996; Spangenberg, 1990).

Self-Directed Search Questionnaire (SDS): The rationale of this questionnaire is to measure interest. The questionnaire fits into the broad context of career planning, since it provides important information relating to an individual's occupational interests, and facilitates the link between personal and occupational information (Owen \& Taljaard, 1996).

SHL Personnel Test Battery (PTB): This is a battery consisting of various tests, used to select clerical and administrative staff. Emphasis is on practical skills and the needs of the modern workplace - including equal opportunity issues (SHL, 1996).

SHL Technical Test Battery (TTB): This is a battery consisting of various tests. It is used in the selection of a wide range of technical staff, including school leavers and work-experienced candidates (SHL, 1996).

Thematic Apperception Test (TAT): This is a projective personality test which is regarded as especially suited to assessing motivation, such as the need for achievement or affiliation (Huysamen, 1996).

Normal Battery (NORM Bat): This battery was designed to measure a number of mental abilities, including mental alertness, computation and certain language skills. It can be used in vocational guidance as well as in the selection of persons with 9 to 10 years of schooling (Huysamen, 1996; Owen \& Taljaard, 1996; Spangenberg, 1990).

Academic Aptitude Test (AAT): The aim of this test is to serve as an aid in the guidance of senior pupils with regard to subject and career choice. More specifically, it provides an assessment of general intellectual ability, verbal ability, mathematical ability and spatial ability. It may also be of value in selection and placement decisions (Spangenberg, 1990).

Programmer Aptitude Battery (PAB): This battery measures aptitude for computer programming. It is intended to be used on individuals who have little or no experience in computer programming, although it might be useful in selecting existing programmers. It should not be used on persons who have not passed matric (Owen \& Taljaard, 1996).

SHL Management and Graduate Item Bank (MGIB): These are verbal and numerical tests designed to assess high level critical reasoning abilities (SHL, 1996).

SHL Critical Reasoning Test Battery (CRTB): These are three tests used to assess verbal, numerical and diagrammatic reasoning skill (SHL, 1996).

SHL Customer Contact Aptitude Series (CCAS): This is a series of tests that assess the verbal and numerical skills required of customer contact staff (SHL, 1996).

Perceptual Battery (Blox): This is a test of spatial relations involving the ability to recognise three-dimensional objects which have been rotated in space and which are represented two-dimensionally as in technical drawings. It predicts success in skilled, technical jobs.
Raven's Progressive Matrices (Raven's): This test consists of designs or matrices from each of which a part is omitted. The subject is required to choose the missing part from six to eight given figures (Huysamen, 1996).

Mechanical Comprehension (Mechanical): This test measures knowledge of mechanical and physical principles. It predicts success in a technically oriented course, particularly the theoretical aspects of such studies, eg engineering technicians and technical apprentices (Owen \& Taljaard, 1996).

\section{Test users (Administrators)}

In Table 4 the various persons responsible for testing in the different organisations, are indicated. Note that these are the test users of the organisations and that they are not necessarily the same people as the representatives who provided the information on each organisation.

\section{TABLE 4}

\section{TEST USERS IN DIFFERENT ORGANISATIONS}

\begin{tabular}{|c|c|}
\hline $\begin{array}{l}\text { Organi- } \\
\text { sation }\end{array}$ & Test user \\
\hline A & $\begin{array}{l}\text { Psychometrists or psychologists. Special manager at head office } \\
\text { overall responsible for testing in company and sees to correct } \\
\text { procedures and standards of testing. }\end{array}$ \\
\hline B & Psychometrists or psychologist. \\
\hline $\mathrm{C}$ & Psychometrists or psychologists. \\
\hline $\mathrm{D}$ & $\begin{array}{l}\text { Use external consulting psychologists. Consulting psychologist } \\
\text { available at head office. }\end{array}$ \\
\hline $\mathrm{E}$ & $\begin{array}{l}\text { No qualified test user. Interpretation done by external consulting } \\
\text { psychologists. }\end{array}$ \\
\hline $\mathrm{F}$ & Psychometrists or psychologists. \\
\hline G & $\begin{array}{l}\text { Psychometrists. Use is also made of external consulting } \\
\text { psychologists. }\end{array}$ \\
\hline $\mathrm{H}$ & Psychometrists or psychologist. \\
\hline I & Use external psychologist and other consultants. \\
\hline $\mathrm{J}$ & Use external consulting psychologist. \\
\hline K & Use external consulting psychologist. \\
\hline $\mathrm{L}$ & Psychometrist or psychologist. \\
\hline M & Psychometrists. Psychologists available at head office. \\
\hline $\mathrm{N}$ & Use external consulting psychologist. \\
\hline $\mathrm{O}$ & $\begin{array}{l}\text { Psychometrists. Use is also made of external consulting } \\
\text { psychologists. }\end{array}$ \\
\hline $\mathrm{P}$ & Use external consulting psychologists. \\
\hline Q & Use external consulting psychologists. \\
\hline $\mathrm{R}$ & No qualified test user. Users trained by test suppliers. \\
\hline S & No qualified test user. Users trained by test suppliers. \\
\hline $\mathrm{T}$ & Use external consulting psychologist. \\
\hline
\end{tabular}

From Table 4 it appears that most of the organisations have their own psychometrists or psychologists. The others make use of trianed test users or external consulting psychologists.

\section{Comments by organisational representatives}

In organisation A they are satisfied with the tests they are using in some areas, and in other areas they are less satisfied. Tests are however useful for the identification of potential in individuals whose scholastic background is not up to standard. Presently 
they are looking at the validity of the tests used and they are attempting to implement more culture-fair tests in future.

According to the feedback from organisation $\mathrm{B}$, the training and qualifications of the person using the test, are very important. The feeling in this organisation is that tests must be used correctly and that although culture-fair tests are the ideal, one has to be realistic - bearing in mind the difficulties in creating them.

In general, organisation $C$ is satisfied with the tests that are being used by them. As long as the tests are used for the purpose for which they were intended, they are seen to be a useful aid. Many of the tests used are however outdated in some places, and should be updated. Because they question the culture-fairness of the tests used, industrial psychologists at their head office have standardized most of the tests on the organisation's population, with resulting norms for different culture groups. Because of the problems relating to culture-fairness, they no longer make use of psychometric tests for the promotion of employees (to evaluate leadership potential). They now make use of a method called Targeted Selection (also known as the assessment interview).

In the case of organisation D there is the perception that they may put too much emphasis on test results. To improve the level of interpretation of results, test results and work performance results are frequently correlated at their head office. Because they are very committed to culture-fairness in their testing, the $16 \mathrm{PF}$ was recently removed from their batteries of tests.

Organisation E seemed generally satisfied with the tests they are using because these proved to test what they purport to test. They however question the culture-fairness of the $16 \mathrm{PF}$.

Overall, in organisation $\mathrm{F}$ they are satisfied with the tests being used. They feel that some of the tests are possibly outdated, especially regarding the norms being used. To an extent the unions are questioning their use of psychometric testing and until tests can undisputedly be proven to be culture-fair, the role of testing will decline in this organisation. There is a feeling that many uncertainties surround the use of tests in the new South Africa. This is one of the reasons why they started using the tests from SHL (which SHL maintains to be culturefair) in this organisation.

In organisation $\mathrm{G}$ the general feeling is that the tests used are culture-fair, but the accompanying norm tables are very outdated. To an extent they also question the reliability and validity of the tests. They want to employ tests that are even more culture-fair and are therefore presently reconsidering their various selection instruments very carefully. They recently bought a test program known as "Potential Index Batteries" (developed by dr P F Erasmus) which is envisaged to solve many of their problems.

According to organisation $\mathrm{H}$, the lack of culture-fairness is a major problem in psychometric testing. This organisation feels very strongly about culture-fair tests because of their multicultural work force.

It appears that organisation I is satisfied with the psychometric testing they employ - they actually intend using these tests even more in future to establish individual potential. They however emphasize that it is only an additional tool used to try and inject some objectivity into what could otherwise be a very subjective process.

The overall impressions from organisation $\mathrm{J}$ is that they are satisfied with the psychometric tests they are using. They also intend using it more often in future. They are of the opinion that there definitely is a need for psychometric tests in the selection procedure. They however feel that it cannot be used on its own - it is part of the whole procedure; it must meet all legal requirements; and the process should be totally transparent.
In organisation $\mathrm{K}$ there seems to be satisfaction with the tests they use for selection purposes, because the tests confirm their selection of candidates who demonstrate good performance. They however also question the issue of the cultural fairness of the tests, and would in future like to see tests developed that will respect cultural diversity.

Also in organisation $\mathrm{L}$ there is concern about the culture-fairness of the tests they are using. It is important to them that tests should not be used in isolation, that one should adhere to the latest legislation and that the tests be standardised for South African conditions. Because they find it so difficult to ensure that tests are culturally fair and non-discriminatory, they are moving more and more towards competency-based assessment.

In organisation $\mathrm{M}$ they are continually evaluating the tests they use and if biased items or tests are found, they are removed, revised, changed or replaced by better ones - if available. There seems to be satisfaction with their testing programs. Their biggest concern presently is to accommodate the new competency-based approach to employment and promotion. According to them, existing tests will need to be reviewed to assess their relevance in terms of competencies.

In organisation $\mathrm{N}$ they are generally satisfied with the tests that they use. There is however a concern that more general education and awareness of the uses and benefits of psychometric testing should occur - for human resource practitioners, management and the general public. They also make use of the "Predictive Index", a checklist with stimuli, which, when responded to, provides measurement of human behaviour and motivation. This index is distributed by Praendex in Johannesburg.

Organisation $\mathrm{O}$ is satisfied with the tests they are using and because they are administered and validated around the world, they believe them to be culture-fair. Their test supplier company is continually researching and updating their test material and data.

Organisation P appears to be satisfied with the tests they are using. It is their belief that the use of psychometric tests as an aid, contributes to the success of their selection process.

In organisation $\mathrm{Q}$ there is concern about the culture-fairness of the tests being used. This is the main reason why they are seriously questioning the use of the $16 \mathrm{PF}$.

Organisation R seems to be satisfied with the tests they are using because it helps them in the selection and promotion process. They feel strongly that tests should never be used on their own.

In organisation $S$ they are satisfied with the methods being used, because they believe they have been helpful in identifying successful candidates.

It is felt by organisation $\mathrm{T}$ that psychometric tests add value to the organisation in terms of competent employees being selected.

\section{DISCUSSION AND RECOMMENDATIONS}

From these investigations into applying psychometric tests in human resource management, it appears that psychometric tests are not used in isolation in practice (see Table 2). As an additional aid used in decision making, the tests normally form part of a defined procedure which includes different, interrelated, specific steps, as well as other tools. It also appears that psychometric tests are not only used for selection purposes, but also for placement, promotion, transfers, training and development. Furthermore, it appears that these tests are often used at different levels in the organisations that participated in this study. 
The tests that are used by these organisations (see Table 3), are mainly South African specific and validated material, distributed by the Human Sciences Research Council, as well as a few other organisations. Most of the organisations included in this survey have test administrators that are trained and qualified test users (see Table 4) who are well aware of the laws and rules that govern psychometric testing in South Africa. To conform to these, the organisations that haven't got trained or qualified test users employed, make use of the services of external consulting psychologists. Adhering to these rules and regulations seems to be a great concern to the majority of these organisations. The researcher therefore concludes that psychometric testing is conducted at a professional level in the organisations surveyed.

This is contrary to a recent world-wide survey into testing and the use of tests (Bartram \& Coyne, 1998) which found that there is a lack of psychologists's involvement in testing. According to them a lack of appropriate training in testing and test use was seen world-wide and almost $60 \%$ of test users were not specifically trained in the use of psychological tests. It was however indicated that the training of testers in inter alia organisational context, was considered to be "fairly adequate". They also found that there is a perception that test mis-use is a problem world-wide and that the best way to counter it is through training and increasing public understanding.

Cook (1997) is also of the opinion that psychometric tests are still sometimes used by people who are not well informed about the issues of measurement and bias. He refers to the fact that the task of the profession is made more difficult by a lack of sophistication among users in the field. According to him, contrary to what was found in the present study, it is clear that tests are still used by some people without a deep understanding of the nature of assessment and the problems associated with it. Under these conditions, information and general education in terms of testing, seem to be the most efficient way of action. Gregoire (1999) mentioned that academic education, continuing education, as well as more publications on test and assessment methods, will raise the competency level on testing and will improve the quality of actions in the professional field - undoubtedly a very important goal in this regard.

From comments by the organisation representatives interviewed in the present study, it generally appears as if they are relatively satisfied with the tests they are using. They also stressed the point that test users must be well trained and tests must be used for the purpose for which they were intended. With her research Rademeyer (1995) also found that although a variety of measuring instruments and alternative assessment techniques are currently being applied in South African organisations, test users display a positive attitude towards psychometric testing and that conventional psychometric tests still play a significant role in the selection process. According to her, it seems as if the use of other assessment techniques, such as simulation exercises, competency-based tests and trainability tests, are considered important, but are not yet really utilized in most organisations.

In his study Cook (1997) found that the majority of respondents were of the opinion that there still is an important role for psychometric testing in the future. The alternatives either lack reliability, or are expensive (eg assessment centres). According to him, provided the issue of bias can be dealt with, psychometric tests offer an inexpensive and time-efficient solution. However, work will have to be done with regard to test construction, validation research and norm collection, the training of test users, and marketing the concept of testing especially with unions. If employers are not to lose the utility which ability testing provides, they will have to support research efforts to validate the newer testing products and promote an extensive education campaign to convince opinion makers that testing is not unfairly discriminatory. Whilst bias can be addressed in research, the issue of fairness remains a political issue which can only be addressed at the political level (Cook, 1997).

According to Huysamen (1996), one of the major stumbling blocks regarding the use of psychometric tests in South Africa, stems from the complexity of creating tests which may be used across a diversity of linguistic and cultural backgrounds. Of major concern are the implications of possible discrimination and therefore many of the organisations in the present study are presently working towards the validation of tests in their own work environments. Based on the frequently expressed needs for culture-fair tests by the representatives of these organisations, it appears that they are aware of the importance to try and implement fair and equal treatment to all individuals.

Cook (1997) also found in his research that considerable awareness of changes in the sociopolitical and economic context of testing, especially in relation to the new labour legislation, was evident. Some companies even dropped testing altogether, however, the general trend seems to be to re-evaluate test batteries carefully and to prepare for possible legal challenges. He found that there is a trend towards dropping the older personality and aptitude tests, but that this is not consistent: some companies are considering beginning to use tests which others are discarding. There also is no clear articulated set of criteria for making these decisions, except for the broad issues of bias and fairness, and the availability of local norms. According to Cook (1997), a trend towards assessment centres and competency-based assessment is also evident.

In this regard it is interesting to note that the $16 \mathrm{PF}$ is by far the most commonly used test by most of the organisations in this study. It is used by 15 of them and the second most commonly used test (SAWAIS) is used by only 6 organisations. Also in her research, Rademeyer (1995) found that by far the most commonly used instrument was the 16 PF. It was used by $45 \%$ of the organisations surveyed in her research. The next most popular instrument was the SORT, used by $23 \%$ of the organisations surveyed in her research.

In the present study the $16 \mathrm{PF}$ is therefore used by all organisations except for five (organisations $\mathrm{D}, \mathrm{H}, \mathrm{O}, \mathrm{R}$ and $\mathrm{S}$ ). Organisation $\mathrm{D}$ recently removed it from their batteries of tests because they found it not to be culture-fair. Another two organisations (organisation $\mathrm{E}$ and $\mathrm{Q}$ ) are still using it, but also question the culture-fairness of specifically the $16 \mathrm{PF}$. Related to this, Abrahams and Mauer (1999) found in a recent South African study that their results did not support the notion of comparability of the constructs of the $16 \mathrm{PF}$ across the four race groups that were included in their investigation. They emphasized the importance to scientifically evaluate all instrumentation used for psychological assessment in South Africa. They then concluded by saying that we simply cannot carry on using assessment instrumentation for which adequate empirical evidence on all applicable psychometric concepts does not exist.

Muniz, Prieto, Almeida and Bartram (1999) studied the situation of test construction and test use in Spanish-speaking and Portuguese-speaking countries. They found the translation and adaptation of tests to be an especially relevant problem. According to them, the commonest problems in the practice of tests were: failure to respect the copyright of the test, use of tests inappropriate to the case, use of out-of-date tests, and failure to check interpretations of tests with other colleagues. The five most commonly used tests in the countries they studied, were (in order of frequency of use): Wechsler Scales, MMPI, Rorschach, Raven's and $16 \mathrm{PF}$. These tests were all used in this present study as 
well - although in this study not the Rorschach, but the SORT was used.

In evaluating the findings of the present study, one has to bear in mind that this was initial, superficial, exploratory research, which involved a relatively small sample. Nevertheless, the findings are indicative of the typical issues that South African organisations are faced with when implementing psychometric testing in human resource management today, and therefore cannot be disregarded. Muniz et al (1999) referred to the fact that tests constitute an excellent tool at the disposition of psychologists. When used correctly and in conjunction with other data, they are invaluable for the practice of the discipline and of great benefit to society. However, when used incorrectly, they can do the discipline great disservice and cause harm to those members of the public whose interests we should seek to protect.

Ultimately psychometric testing and development is undergoing an unstable period in the history of its use. It therefore comes as no shock that some companies are concerned, uncertain and worried about the latest legislation and the use of psychometric tests. Despite this, it however appears that organisations are attempting to adapt to the instability and uncertainty while continuing to identify and develop the human resource potential of South Africa. It is a known fact that well developed psychometric tests are much more valid and fair than many other selection methods, eg unstructured screening interviews. The right kinds of tests that are culture-fair and administered by qualified people, can therefore be of great help to organisations in meeting their human resource objectives.

Given the critical demands which are likely to be placed on the profession in the next few years, there is a need for collaboration between test users to establish policies and to support research directed at providing industry with usable instruments to identify talent fairly and efficiently (Cook, 1997). In the present study mention was frequently made by the organisation representatives that certain of the tests and test material being used, were vastly outdated - a serious accusation against psychometric material. It therefore seems to be a sensible suggestion that test manuals and other test material (also norms) should be updated more frequently by the distributor of a test.

Chan, Drasgow and Sawin (1999) found with their research that time has an effect on the effectiveness of psychological items and tests. They found that certain types of cognitiveability measures are more susceptible to the effects of time than others. They also warned that test developers and test users should pay attention to the shelf life of their tests especially large scale and well-established non-cognitive measures, such as inter alia the $16 \mathrm{PF}$. According to them, it is possible that over time such measures may be less stable than cognitive measures. Although this regular updating of test material might be regarded by some as very idealistic, the negative implications of not adhering to these guidelines, must not be underestimated.

Consideration should also be given to the development of new tests, with urgent special emphasis on culture-fairness - which could possibly be enhanced by implementing competencybased assessment, as it is job-related rather than norm-based. Here it must be born in mind that competency-based assessment measures current ability or achieved competence, while psychometric testing attempts to assess potential for development.

With regard to personality tests, Cook (1997) is of the opinion that the difficulty of designing a questionnaire which is applicable across the cultural and linguistic range of candidates in South Africa, appears to be insurmountable. He suggested that what could work well and would be defensible in court, would be to identify specific attributes that are demonstrably job-related, then use an instrument which can be shown to measure that specific attribute with reasonable validity across groups. This, he said, would be easier to establish than validating a personality test as a whole. He therefore recommended that personality tests should only be used for selection purposes where the job requirements clearly indicate specific traits measured by the test, and then only in conjunction with other information. According to him, the use of clinically-oriented tests in a cross-cultural South African context does not seem to be justified by the current state of knowledge.

Presently it is very important that tests be validated for the different organisations in which they are used. This also implies that in each organisation, for each specific job, the validity of the test battery being used, must be ensured. Once again this is something which could possibly be enhanced by also making use of competency-based assessment, which is directly linked to job content and inherent job requirements. One must however once again bear in mind that there are psychological factors which competency measures cannot provide, such as that of learning or developmental potential.

Although this study was a qualitative investigation, it was not always possible to obtain all the detailed information normally required in this type of study. One possible reason for this is that organisations often regard some psychometric information as confidential. With regard to follow-up research, an expansion of the sample can be considered. This would also lead to a more in-depth study of the entire field of psychometric testing in human resource management.

Lastly, the cooperation of everybody involved in this study, as well as all participating organisations, is greatly appreciated.

\section{REFERENCES}

Abrahams, F. \& Mauer, K.F. (1999). The comparability of the constructs of the $16 \mathrm{PF}$ in the South African context. Journal of Industrial Psychology, 25(1), 53-59.

Aiken, L.R. (1994). Psychological testing and assessment. (8th Ed). Massachusetts: Allyn \& Bacon.

Anastasi, A. \& Urbina, S. (1997). Psychological testing. (7th Ed). New Jersey: Prentice-Hall Inc.

Bartram, D. \& Coyne, I. (1998). The ITC/EFPPA survey of testing and test use in countries world-wide: narrative report. Paper presented at workshop of International Test Commission, Dublin.

Chan, K., Drasgow, F. \& Sawin, L.L. (1999). What is the shelf life of a test? The effect of time on the psychometrics of a cognitive ability test battery. Journal of Applied Psychology, 84(4), 610-619.

Cook, J. (1997). Report on a survey of psychometric testing in South African companies. Unpublished report done for South African Breweries Beer Division.

Eckstein, S. (1998). Testing Times. People Dynamics, 17(6), 54-55. Employment Equity Act. (1998). No.55. Republic of South Africa.

Friedenberg, L. (1995). Psychological testing: Design, analysis, and use. Massachusetts: Allyn \& Bacon.

Gregoire, J. (1999). Emerging standards for test applications in the French-speaking countries of Europe. European Journal of Psychological Assessment, 15(2), 158-164.

Huysamen, G.K. (1996). Psychological measurement. An introduction with South African examples. Pretoria: J.L. van Schaik.

Kemp, N. (1999). Psychometric testing is not dead. People Dynamics, 17(3), 14-17.

Kriek, H. (1998). Fairness and equity: New legislation will help to increase the best practice of occupational testing. Jul/Aug Newsline, SHL South Africa. 
Medical, Dental and Supplementary Health Service Professions Act. (1974). No.56 as amended. Republic of South Africa.

Mittner, M. (1998). Psychometric tests under fire. $F \& T$ Weekly, 26 June, 56.

Muniz, J., Prieto, G., Almeida, L. \& Bartram, D. (1999). Test use in Spain, Portugal and Latin American countries. European Journal of Psychological Assessment, 15(2), 151-157.

Owen, K. \& Taljaard, J.J. (1996). Handbook for the use of psychological and scholastic tests of the HSRC. Pretoria: HSRC.

Rademeyer, A. (1995). The application of psychometrics in South African organisations within a changing labour market. Unpublished masters dissertation, University of Pretoria.

Roodt, G. (1998). Challenges in psychological assessment. People Dynamics, 16(11), 30-34.

Schultz, D.P. \& Schultz, S.E. (1998). Psychology and work today. (7th Ed). New Jersey: Prentice-Hall Inc.
SHL (1996). Assessment materials. Saville \& Holdsworth Ltd. Occupational Psychologists.

Spangenberg, H. (1990). Assessing managerial competence. Cape Town: Juta.

Thomas International (undated). Increasing people effectiveness. Proceedings of a two day workshop presented by Thomas International Management Systems.

Van der Merwe, R.P. (1999). Psychological assessment in industry. Journal of Industrial Psychology, 25(3), 8-11.

Van der Merwe, R.P. (2000). The application of psychometric tests in human resource management. South African Journal of Economic and Management Sciences, 3(2), 290-307.

Van der Walt, H.S. (1998). Psychological tests: Refined instruments for reliable information to decision-makers. In Focus Forum, 5(4), 16-17. 